\title{
Teaching Research on "Experience" Architecture History with VR Technology
}

\author{
Yanru Ge \\ Binzhou University, Binzhou, Shandong, 256600
}

\begin{abstract}
As a compulsory course for students, the history of architecture is characterized by a large knowledge system, a theoretical paradox, and a low degree of acceptance of college students. The major universities are constantly exploring the reform of the teaching methods of architectural history.

In today's information age, the use of VR technology to assist teaching is a very active and effective means, rational allocation of time as well as the full use of virtual reality technology making the teaching style of architectural history more diverse, so that students' learning enthusiasm is effectively improved, It is a new teaching method that we should actively explore.
\end{abstract}

Keywords: architectural history; VR; experiential

DOI: $10.36012 /$ fhe.v1i1.569

$\mathrm{W}$

hen it comes to the teaching of architectural history, it is no stranger to each architect. The history of architecture is a compulsory course for students. The credits are the most in the theoretical course.In undergraduate teaching, the main teaching content of architectural history emphasizes the basic historical facts, and the goal is to improve students' theoretical literacy and design literacy.However, the history of architecture has a long history, from ancient times to modern times. It covers a wide range of countries, including Western Europe,

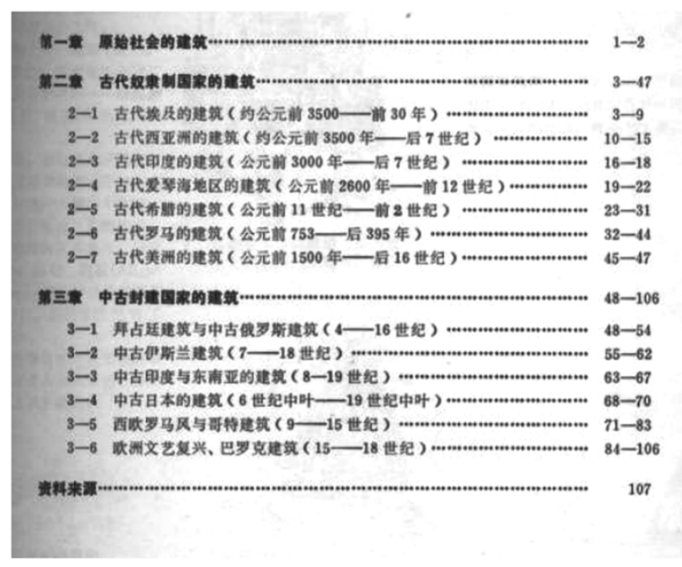

Figure 1

\section{Problems in inquiry}

\section{1 linear historical teaching}

The two textbooks of Chinese architectural history and foreign architectural history are mainly written with
Eastern Europe, Africa, America, East Asia, Southeast Asia and West Asia. It has many contents, such as diachronic development, famous architecture, theoretical books and architectural thoughts.In recent years, with the development of information technology, the channels for students to acquire knowledge have increased. In the education and teaching of architecture undergraduate, the teaching of architecture history is difficult and the acceptance of students is quite poor, which has become a prominent problem in major universities.

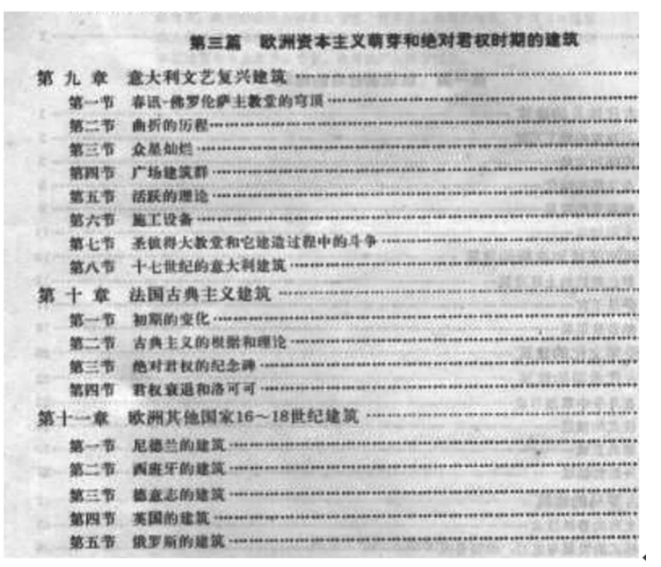

Figure 2

the timeline as the main thread (Fig. 1,2). Each historical development stage includes many contents, such as social culture, economic development, technological development and art. These parts are the essence of 
the history of human development, which is difficult to choose. However, if the professor is flat, the students' interest and enthusiasm for learning will not be high.

\subsection{Classroom teaching methods are single}

In recent years, with the development of information technology, our classroom teaching style has gradually changed. From the simple use of blackboard and teaching materials to the use of multimedia-assisted teaching, the intuitiveness of knowledge display has been greatly improved, But once take 90 minutes of class, this simple form of theoretical teaching still left students exhausted and the acceptance of it is still poor.

\subsection{The theoretical logic of the course is strong}

Architectural history, especially the modern history of architecture in the West, theoretical works and architectural phenomena emerge in an endless stream. As an undergraduate student of architecture, there is not much contact with foreign historical environment and architectural environment. It is almost completely strange, leading to the teaching of this part especially difficult.

\section{Explore the "experience" teaching method}

There are many problems in the teaching of architectural history, and it is difficult to solve them completely. The three questions raised here are the most prominent problems in the teaching of architectural history. It is not difficult to find that they all point to the problem of knowledge transfer methods and the lack of interest of students. The teaching team of Chongqing University also puts forward the problems in the process of students' learning according to their own teaching practice experience. They find that under the traditional teaching mode, students' thinking and cognitive activities are one-way mobility and lack of thinking. To be active, students are prone to knowledge and cognitive fatigue, and the teaching effect is widely questioned." [Research on the Experiential Teaching Method of Architectural History--An Experimental Report on the Teaching Reform of Foreign Architecture History of Chongqing University" Liu Zhiyong, Zhang Xingguo, Du Chunlan, Li Zhen, Higher Architecture Education, Vol. 20, No. 3, 2011]

With the reform of teaching methods, the major construction universities in China are constantly updating their teaching styles. Among them, Chongqing University and Zhejiang University of Technology have put forward the "experience" teaching method.
Teachers at Zhejiang University of Technology mentioned that "all historical buildings, designers are trying to find people who are close to and into the building (whether evangelists, kings, believers, people) to find a "perceived" experience. These experiences are further transformed into an ideographic structure, which is a building model that has been understood and passed down by the inhabitants of previous generations." [Study on the Multi-Dimensional "Progressive Experience" Teaching Method of "Foreign Architecture History" Course, Yang Xiaoli Feng Jing, Zhuang Chengyu, theoretical research, 2017.06]. The American popular historian Fang Long also said that "feeling history is more important than understanding history." Tracing the purpose of our architecture teaching, students' real experience of historical architecture is, to a certain extent, the fundamental purpose of our teaching.

\section{Combination of VR technology and archi- tectural history teaching}

\subsection{VR Technology Overview}

According to the encyclopedic entry written by Science Popular Science, virtual reality technology (English name: Virtual Reality, abbreviated as VR), developed from the end of the last century, is a brand new practical technology. In theory, the focus of virtual reality technology (VR) is to use computers to create and experience virtual worlds. It is a simulation system that uses computers to generate a simulation environment that allows people to immerse into the virtual environment through certain external devices.

From 1929, Edward Link designed the simulator for training pilots, which has been in development for 90 years. "The main functions are divided into planning and design, display entertainment, training drills, etc. The planning and design system can be used for experimental verification of new facilities, which can significantly shorten the development time, reduce design costs, improve design efficiency, Can be used in urban drainage,community planning and other fields. such as VR simulation water supply and drainage system, can greatly reduce the funds originally needed for experimental verification." [Xu Yifu. Development of virtual reality technology [J]. Science and Technology Communication, 2018, 10 (23): 122-123, 130]. During this period, the three-dimensional image generation technology of VR technology, and multi-sensor interaction technology developed rapidly, produced a vari- 
ety of virtual environment interactive experience system. Common features of these systems are: immersion, interactivity, multi-perception, conception, and autonomy. Immersion is the core feature of virtual reality technology. It manipulates the user's perception and enables users to quickly enter the virtual environment of computer simulation to gain a realistic feeling. 3.2 The development of VR technology in education The passive factors that exist in the teaching of architectural history have been mentioned above. The cog- nitive fatigue of students' knowledge of architectural history is a problem that has been difficult to solve for a long time. In view of this, various colleges and universities are also actively preparing their own virtual laboratories to change the status quo of in which students have fixed seat and were indoctrinated knowledge blindly, blindly indoctrinated knowledge, thereby improving students' understanding of knowledge points strengthening their memory and understanding of knowledge points.

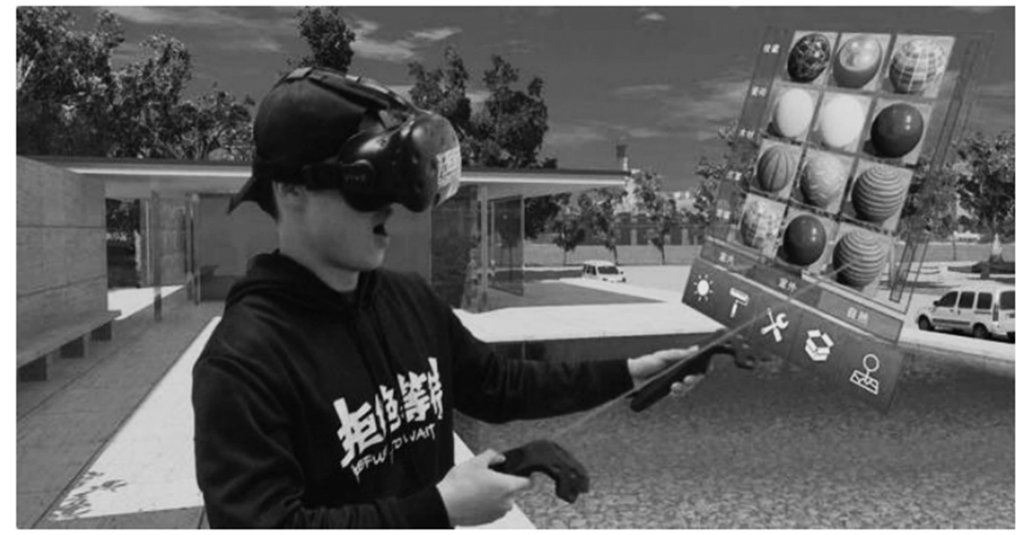

Figure 3 The display of the model

\subsection{Research on VR Technology with Mars Soft- ware as an Example}

As a self-developed building visual effects software, Mars focuses on the display of architecture. Mars differs from traditional rendering software in that Mars software can be combined with VR technology to provide users with a virtual scene experience, and to edit and change virtual environments in both PC and VR devices (Figure 3). In VR mode, users can experience the real scenes of these historical buildings, feel the scale, materials, space and structure of the building, intuitively understand the incomprehensible knowledge in the book, and compare the ordinary multimedia two-dimensional pictures and videos. The presentation of VR technology enables students to be immersed in it. "The immersion of virtual reality technology depends on people's perception system. When users perceive the stimulation of the virtual world, including touch, taste, smell, and motion perception, they will Resonating with thinking, causing psychological immersion, feeling like entering the real world" [Dá mí n. Application research of virtual reality technology [J]. Computer fans, 2019, (1): 53.] Through the activities of the body to feel the building, greatly Increase the participation of students in class, and can

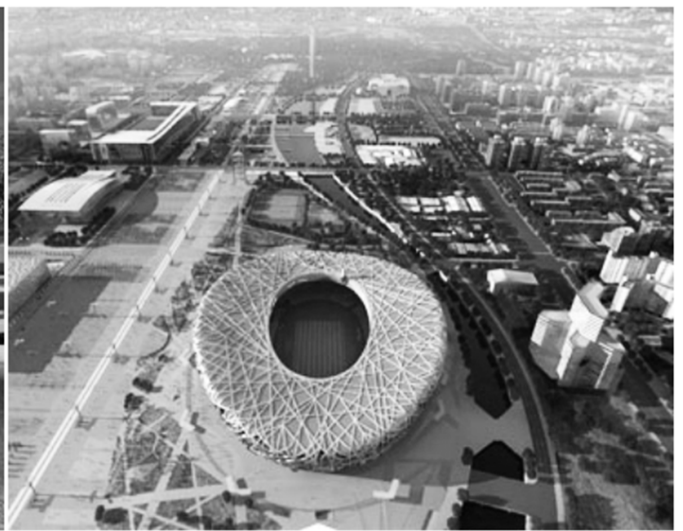

Figure 4

greatly enhance students' impression of knowledge points.

\section{Application of VR technology in the teach- ing of architectural history}

\subsection{Teacher's display of historical building models}

Due to the limitations of class time, many background knowledge and theoretical study are indispensable. Only some important historical buildings can be selected to provide students with VR experience. Most of the historical buildings need to rely on the teacher's computer. Mars software can be rendered in real time without transmission. Teachers can use the computer to switch between scene effects and animation playback through shortcut keys, interact, edit and modify the content in real time to achieve new interactive renderings and animations (Figure 4).

\subsection{Student production model}

Due to the incomplete construction resources in Mars' network resource library, there may be problems in the process of teaching that some historical buildings are missing. "The establishment of virtual environment is the core content of VR system, the purpose is to obtain the three-dimensional data of the actual environment, and establish the corresponding virtual environment 
model according to the needs of the application." [Tang Peng, Zhang Hui. Talking about virtual reality technology[J] The Guide to Knowledge, 2018, (36): 50-51.] Given that Mars software can be well compatible with model making software. You can use the network resources to find the required historical building models for rendering and immersive experience, but these models lack the historical data when they are produced, and there are various problems. Through learning, students can find out the problems in the model and modify them through the editor. It is also a good way to strengthen memory and understand the knowledge points.

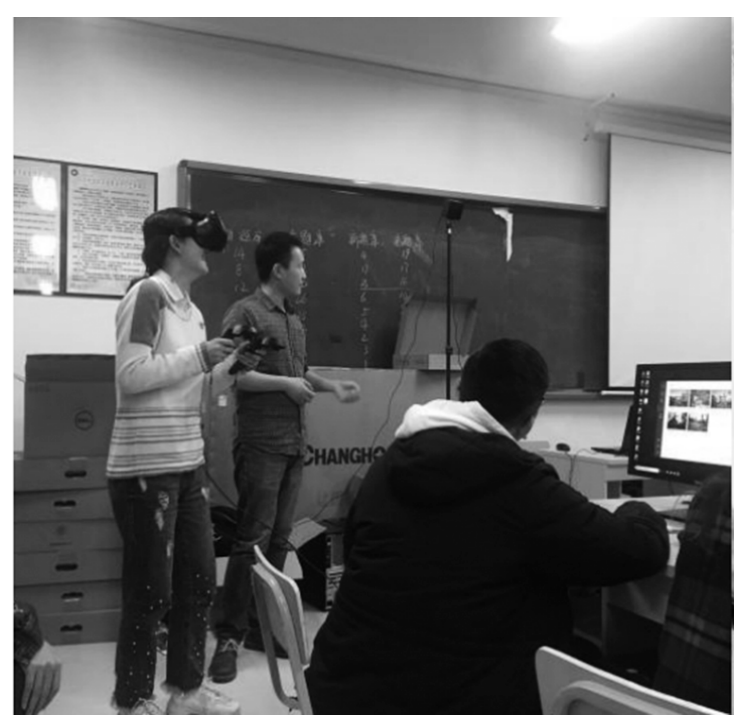

Figure 5

\subsection{Student immersive experience}

According to the characteristics of the course of architecture history and the law of students' fatigue, the design of teaching links is reasonable. At the beginning of the design of the teaching session, we first need to answer a few questions, that is, "Let the students experience what they experience - how to adjust the content of the experience, how to experience the students - how to choose the experience mode, how to experience it - the experience process Asked in the form of organization." [Research on the Experiential Teaching Method of Architectural History--An Experimental Report on the Teaching Reform of Foreign Architecture History of Chongqing University" Liu Zhiyong, Zhang Xingguo, Du Chunlan, Li Zhen, Higher Architecture Education, Vol. 20, No. 3, 2011] Taking the Acropolis as an example, the Acropolis base has a complex environment, a large building, a typical structure and a close connection with the environment, and as a representative work of ancient Greek architecture, it has far-reaching influence in the history of architecture. How to arrange the class time reasonably is very important. The Acropolis's teaching time is 45 minutes. First, the Acropolis is first outlined for $15 \mathrm{~min}$ utes. Then students are allowed to experience $10 \mathrm{~min}$ -

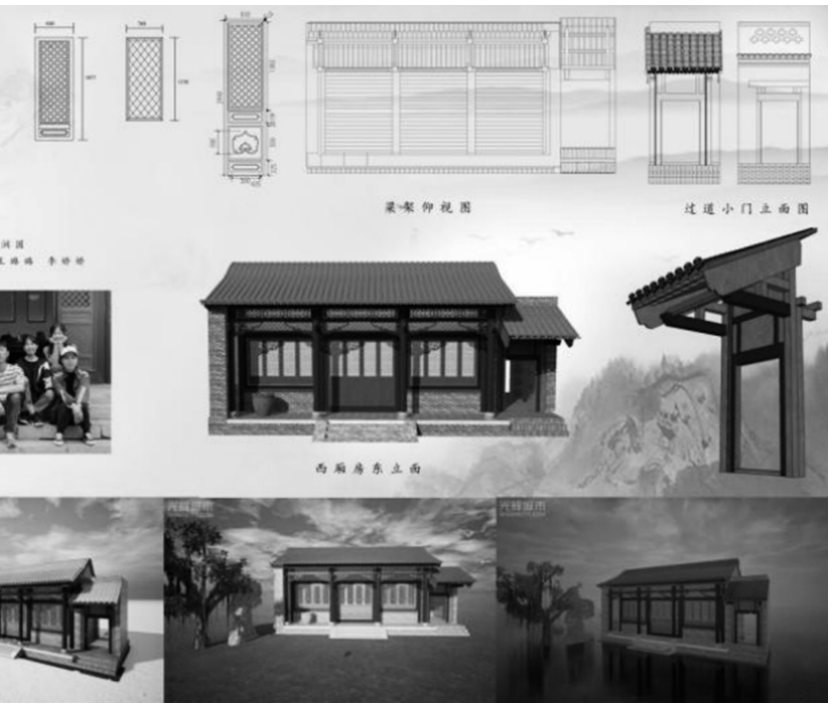

Figure 6

utes in the virtual model of the Acropolis with VR equipment. The rest of the time is operated by the teacher and leads the students to follow. The pilgrimage route explains each building. Such class schedules, students learn a variety of ways, each period of learning time is controlled within half an hour, effectively reducing the occurrence of student fatigue, and also the key knowledge in the experience. (Figure 5)

\subsection{Student post-class model making operation}

Just watching or experiencing, lack of practice in mastering knowledge points, will still not be profound enough. The design of homework is also essential. The job is based on modifying existing virtual model errors and reconstructing historical building virtual models. Among them, The reconstruction of historical building model is of heavy workload, long construction period and high difficulty. It is difficult for a student to complete in a short time. In order to ensure the quality and motivate students to learn, Students will be grouped according to the size and difficulty of the construction model. Size determines the number of members in each group to ensure a balanced work and difficulty.

This year, We conducted a course construction survey with 28 third year undergraduate students, students were divided into five groups according to the 
number of buildings, and each group was assigned a different number of students according to the workload and difficulty of each group. Five days of mapping, five days of model making, and eventually an animated showcase. (Figure 6) Through this way of learning, students' interest in architectural history through this type of learning has greatly increased, and the mastery of knowledge points has become stronger.

Traditional education only instills knowledge into students. Nowadays, virtual reality technology can help students to create a vivid and realistic learning environment, so that students can enhance their memories through real feelings. Compared with passive infusion, virtual reality technology is used. Self-directed learning is more acceptable to students, which is more likely to stimulate students' interest in learning. [Shi Yuhang. On the development status and application of virtual reality [J]. Chinese information, 2019, (1): 20.] In view of the frontier and advantages of VR technology, rational use of VR technology in the teaching of architectural history, is an important subject worthy of serious study and practice by our undergraduate educators.

Picture 1, 2, 5, 6 author self-painting

Picture 3, 4 from the web https://forum.sheencity. $\mathrm{com} /$

[1] Virtual-reality heritage presentation at Ename. Pletinckx, D., Callebaut, D.,Killebrew, A.E.,Silberman, N.A. Multimedia,
IEEE . 2000

[2] "Experimental Teaching Method of Architectural History--An Experimental Report on the Teaching Reform of Foreign Architecture History Course of Chongqing University" Liu Zhiyong, Zhang Xingguo, Du Chunlan, Li Zhen, Higher Architecture Education, Vol. 20, No. 3, 2011

[3] Virtual laboratories for education in science, technology, and engineering: A review $[\mathrm{J}]$. Veljko Potkonjak,Michael Gardner,Victor Callaghan,Pasi Mattila,Christian Guetl, Vladimir M. Petrovi, Kosta Jovanovi. Computers \& Education. 2016

[4] "Multi-dimensional "gradual experience" teaching method of "Foreign Architecture History" course", Yang Xiaoli, Feng Jing, Zhuang Chengyu, Theoretical Research, 2017.06

[5] Brief introduction of virtual reality\&its challenges. Mandal S. International Journal of Scientific\&Engineering Research . 2013

[6] Investigating learners' attitudes toward virtual reality learning environments: Based on a constructivist approach [J]. Hsiu-Mei Huang, Ulrich Rauch, Shu-Sheng Liaw. Computers \& Education. 2010 (3) Research on Virtual Teaching Application of VR Technology, Azimkulov Ayan, Master's Journal Library, 2017.01.15

[7] Virtual laboratories for education in science, technology, and engineering: A review [J]. Veljko Potkonjak,Michael Gardner, Victor Callaghan, Pasi Mattila,Christian Guetl, Vladimir M. Petrovi, Kosta Jovanovi. Computers \& Education. 2016

[8] $\mathrm{Xu}$ Yifu.Discussion on the development of virtual reality technology [J].Science and Technology Communication, 2018,10(23):122-123,130. 